NASA Technical Memorandum 107045

AIAA-95-2834

5322

$p=12$

\title{
Application of Thin-Film Thermocouples to Localized Heat Transfer Measurements
}

J. Lepicovsky

NYMA, Inc.

Brook Park, Ohio

R.J. Bruckner and F.A. Smith

Lewis Research Center

Cleveland, Ohio

Prepared for the

31st Joint Propulsion Conference and Exhibit cosponsored by AIAA, ASME, SAE, and ASEE

San Diego, California, July 10-12, 1995

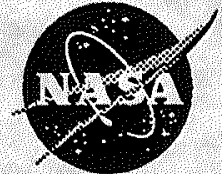

National Aeronautics and Space Administration

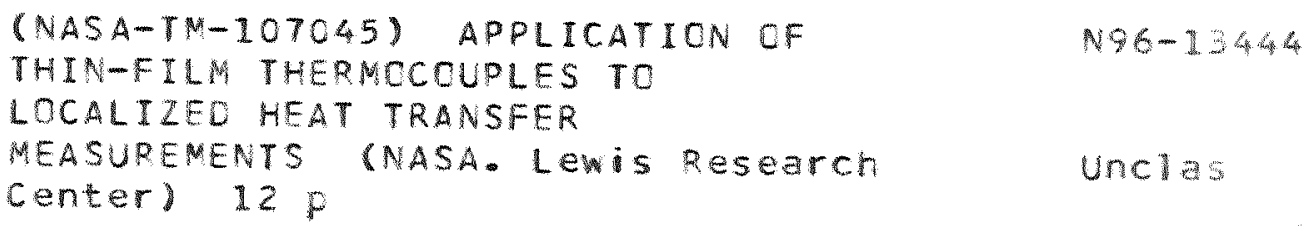




\title{
Application of Thin-Film Thermocouples to Localized Heat Transfer Measurements
}

\author{
J. Lepicovsky ${ }^{*}$ \\ NYMA, Inc., Brook Park, OH 44142 \\ and \\ R.J. Bruckner ${ }^{\dagger}$ and F.A. Smith \\ NASA Lewis Research Center, Cleveland, $\mathrm{OH} 44135$
}

\begin{abstract}
The paper describes a proof-of-concept experiment on thin-film thermocouples used for localized heat transfer measurements applicable to experiments on hot parts of turbine engines. The paper has three main parts. The first part describes the thin-film sensors and manufacturing procedures. Attention is paid to connections between thin-film thermocouples and lead wires, which has been a source of problems in the past. The second part addresses the test arrangement and facility used for the heat transfer measurements modeling the conditions for upcoming warm turbine tests at NASA LeRC. The paper stresses the advantages of a modular approach to the test rig design. Finally, we present the results of bulk and local heat flow rate measurements, as well as overall heat transfer coefficients obtained from measurements in a narrow passage with an aspect ratio of 11.8. The comparison of bulk and local heat flow rates confirms applicability of thin-film thermocouples to upcoming warm turbine tests.
\end{abstract}

\section{List of Symbols}

$\begin{array}{ll}\operatorname{Re}_{C_{-} O} & \\ & \\ R e_{H_{-} 3} & \\ & \\ q_{L} & {\left[k W \cdot m^{-2}\right]} \\ Q_{T} & {[W]} \\ q_{B} & {\left[k W \cdot m^{-2}\right]} \\ U_{T} & {\left[W \cdot K^{-1} \cdot m^{-2}\right]} \\ \Delta T_{S_{-} H C} & {[K]}\end{array}$

Reynolds number, coolant side, at the entrance to the cooling passage Reynolds number, hot-gas side, at the centerline of the test module local heat flow rate total heat transfer bulk heat flow rate overall heat transfer coefficient difference of hot-gas and coolant static temperatures

* Senior Supervisor, Experimental Fluid Dynamics Section, Associate Fellow AIAA

$\dagger$ Operation Engineer, Member AIAA

\section{Introduction}

Efficient turbine blade cooling in high performance jet engines, coupled with minimum requirements on the amount of cooling air, has recently become a critical issue in engine developments. Local hot spots on the blades, which may form due to non-uniform cooling, can impose severe limitations on an engine's performance and structural integrity. The primary cause of these hot spots is an inadequate cooling design that occurs due to a lack of detailed knowledge of local heat transfer coefficients on the internal walls of cooling passages. Advances in analytical and computational techniques used to determine heat transfer and surface temperature distributions on turbine blades have led to the need to verify analytical predictions experimentally. However, the existing conventional experimental techniques are not sufficient for this purpose, and advanced optical techniques are virtually impossible to apply inside narrow cooling passages. 
Turbine blade temperature and heat transfer measurements are presently accomplished by embedding conventional thermocouples in the blade walls. The uncertainty in this method of measurement can be as high as $50 \mathrm{~K}$ [1] because of heat path distortion, uncertainty of exact location of thermocouple junctions, and perturbation in the coolant flow pattern caused by "bulky" thermocouple wires very often routed through narrow cooling passages. On the other hand, the emerging thin-film thermocouples appear to be an ideal solution for blade and vane surface temperature measurements [2]. Very fine thin-film sensors (the overall thickness is less than $15 \mu \mathrm{m}$ ) guarantee virtually no perturbation of the heat flow path and wall thickness or of the coolant flow pattern. Thin-film sensors technology is rapidly maturing into a reliable experimental technique. Even though some recent attempts to measure the blade surface temperatures using thin-film sensors were not fully successful [1], the failure was not caused by thinfilm sensors on the blades but rather by problems with the thin-film-to-lead-wire connections.

NASA Lewis Research Center (LeRC) has established a thin-film sensor laboratory [2] to enhance the technology of thin-film thermocouples for applications in turbine engine research. To verify and master the experimental methodology of thin-film thermocouples, we decided to carry out first experiments in a controlled test environment before applying these sensors to engine tests.

The paper reports proof-of-concept experiments; it has three main parts. The first one describes the thin-film sensors and manufacturing procedures. The second part addresses the test arrangement and facility used for the heat transfer measurements modeling the conditions for upcoming warm turbine tests at NASA LeRC. Finally, the results of bulk and local heat flow rate measurements are presented, as well as overall heat transfer coefficients obtained from measurements in a narrow passage with an aspect ratio of 11.8 .

\section{Thin-Film Thermocouples}

Thin-film thermocouples are very fine temperature sensors (less than $15 \mu \mathrm{m}$ thick) that are manufactured on a particular surface by a sputtering process. The technology of thin-film thermocouples was improved under NASA LeRC contracts and is described in Refs. 3 through 5. Recently, the thin-film thermocouple technology was advanced at NASA LeRC and at present is ready for engine applications, on an experimental basis, to measure surface temperatures and local heat transfer rates on hot parts of turbine engines. Currently, the sputtering at NASA LeRC is made in radio frequency (RF) sputtering chambers. The material to be sputtered forms a part of a cathode connected to a high voltage (up to $2400 \mathrm{~V}$ ), high frequency $(13.56 \mathrm{MHz})$ source. During the process, molecules of the target material are knocked out from the cathode; on their way to an anode, they are deposited on a desired surface placed in their path. The sputtering is done in argon environment at an absolute pressure level of $0.13 \mathrm{~Pa}$. The RF sputtering was selected because this process permits deposition on both alloy and ceramic materials with good adhesion.

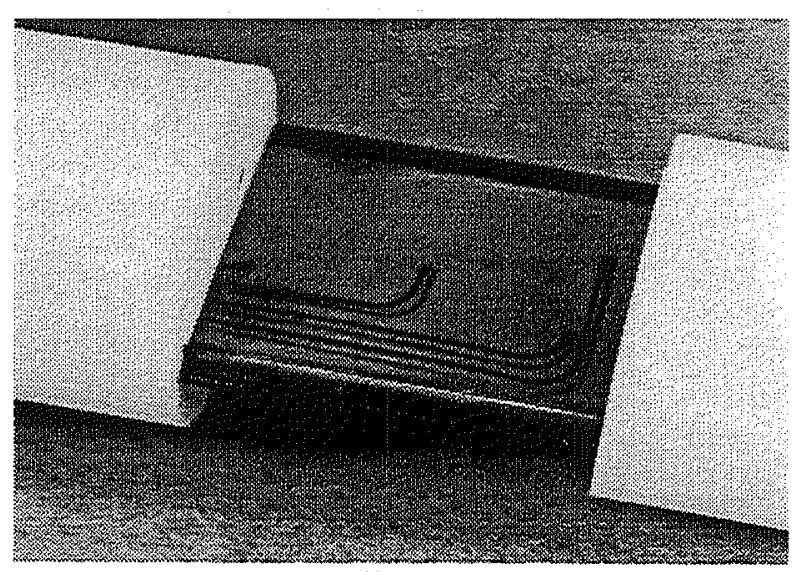

Fig. 1 Test article instrumented with four thin-film thermocouples.

Fig. 1 shows a test article instrumented with four thin-film thermocouples on its external surface. The test article is a flat piece with a slit-like rectangular cooling passage inside. The inner passage wall is also instrumented with four thermocouples at the same locations (not visible in the photograph). The thermocouple junctions, as well as four pairs of thermocouple legs, seen in Fig. 1, are made by sputtering. A magnified view showing a typical thinfilm thermocouple is in Fig. 2. As seen in this picture, the sensor consists of several layers deposited on the test article surface. The manufacturing process for thin-film sensors begins with a rigorous cleansing of the substrate surface (blade, vane, or test article 


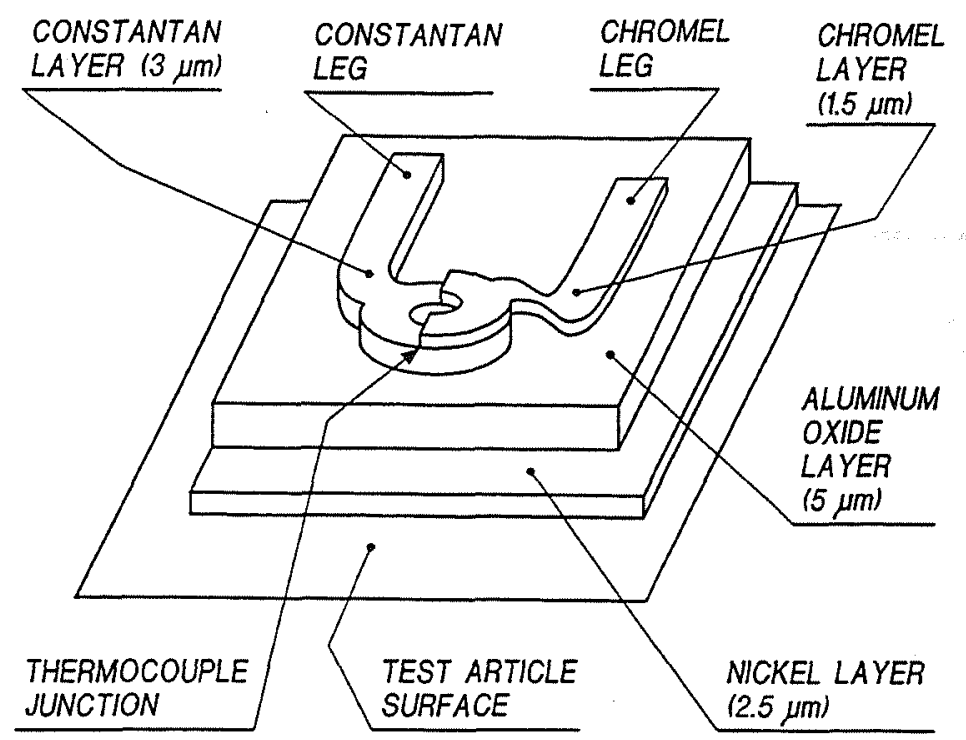

Fig. 2 Thin-film thermocouple (Type E).

surface) to remove oxidation and contaminants. Then, the process involves sputtering a bond coat of nickel layer $(\approx 2.5 \mu \mathrm{m})$ onto the surface. The nickel adheres very well to a surface and significantly reduces possibility of a sensor failure due to adherence loss.

The second phase of the process involves depositing approximately a $5 \mu \mathrm{m}$ layer of aluminum oxide to isolate the thermocouples electrically from the substrate. However, the aluminum oxide layer must be deposited on top of the nickel immediately to prevent nickel from oxidizing. To accomplish that, there must be two cathodes in the sputtering chamber -- one with nickel and one with aluminum oxide. Immediately after the nickel deposition is completed, the aluminum oxide cathode is turned on and sputtering resumes. When this is done, the article is removed from the chamber and the electrical resistance of the aluminum oxide layer must be checked. If a minimum of $30 \mathrm{M \Omega}$ resistance to ground is measured at selected check points, the process can continue for the next phase; otherwise it must be repeated from the beginning.

The next phase is the construction of the actual thermocouple. The selected thermocouple is type ' $E$ ' (constantan-chromel). At first, a $3 \mu \mathrm{m}$ layer of constantan is sputtered on top of the aluminum oxide layer. Then, the would-be junction and the constantan leg path are masked with a dry transparency and the remainder of the constantan layer is chemically etched away. In the next step, half of the would-be junction is unmasked but the constantan leg path remains covered. Now, a $1.5 \mu \mathrm{m}$ thick layer of chromel is deposited on the surface. This is followed by suitable masking of the chromel leg path; then the rest of the chromel layer is etched away. Finally, the masking is washed off using acetone; the thin-film thermocouple is completed. To protect the sensor from erosion, a thin layer of aluminum oxide can be deposited over the entire instrumented surface. This operation was not performed for the current testing but will be for future turbine tests.

Mastering the thin-film thermocouple sputtering technology, however, is not sufficient for performing temperature measurements on engine components. An integral part of the problem is splicing the thin-film thermocouple legs to lead wires to connect the sensors with data acquisition equipment. After all, several attempts to use thin-film thermocouples in engine environment failed solely because of problems with the thin-film-tolead-wire connections [1].

In the NASA LeRC approach, the sputtered thermocouple legs were first connected to bare $25 \mu \mathrm{m}$ thermocouple alloy wires which were then connected to $0.25 \mathrm{~mm}$ insulated thermocouple lead wires. Fig. 3 shows the first connection for the thermocouples on the inner wall of the test article.

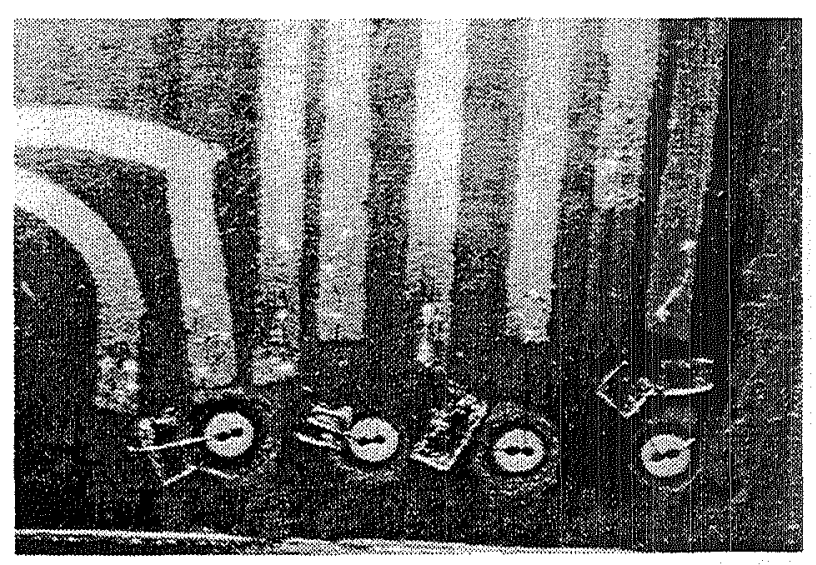

Fig. 3 Thin-film/bare lead wire connections on the inner wall of the test module. 
Because the surface of the test article was covered with the aluminum oxide layer, the wires were insulated from the substrate. The bare wires were gap welded to the thin-film legs using two parallel electrodes. To get the wires through the wall on the external surface, four aluminum oxide double-hole plugs were inserted in the wall (white circles in Fig. 3). The second connection to the insulated lead wires was made in one of the flanges of the test piece. Lead wires were cemented in the flange and then ground flush with the surface. Fig. 4 illustrates this stage of operation. After that, the bare wires were spot-welded to the lead wires as seen in Fig. 5. To back-up the electric connection, the welds were covered with electrically conductive epoxy, which proved very reliable. We did not lose any of the six thin-film thermocouple sensors during the testing. Originally, however, eight sensors were manufactured; two of them did not satisfy the resistance-to-ground check and were not used.

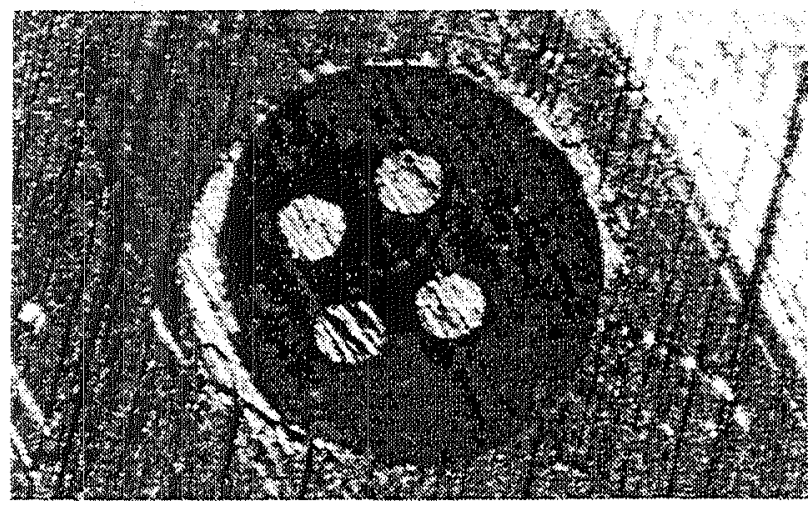

Fig. 4 Flush ground insulated lead thermocouple wires in a flange of the test module.

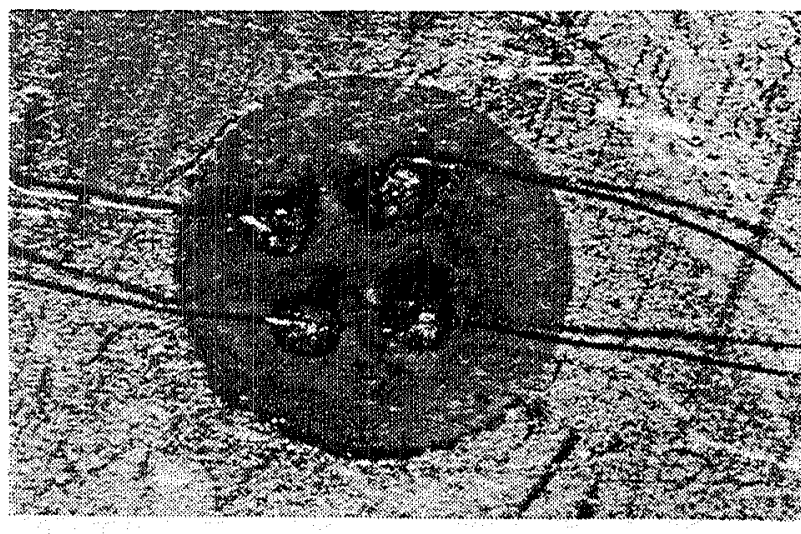

Fig. 5 Spot welds of bare and insulated thermocouple lead wires of the connection on the test module flange.
All thin-film thermocouples for this experiment were calibrated using a NIST traceable platinum RTD as the standard. Calibration results were compared to the IPTS-68 and ITS-90 thermocouple standards. A review of the calibration data indicated that the thinfilm thermocouples required no special treatment with respect to signal conversion and data acquisition to achieve a measurement uncertainty equivalent to standard thermocouples.

\section{Heat Transfer Test Arrangement}

The test arrangement was designed to model flow and heat transfer conditions, in terms of $\mathrm{Re}$ and $\mathrm{Ma}$ numbers, typical for cooled components of turbine engines using a simple and controllable geometry. In essence, the test article consists of an internally cooled flat plate submerged into a stream of heated air. The principle is shown in Fig. 6. A simplified section of the test rig is shown in Fig. 7; a photograph of it is in Fig. 8. The photograph shows the test section with a removed side wall to expose the cooled flat plate in the middle of the channel.

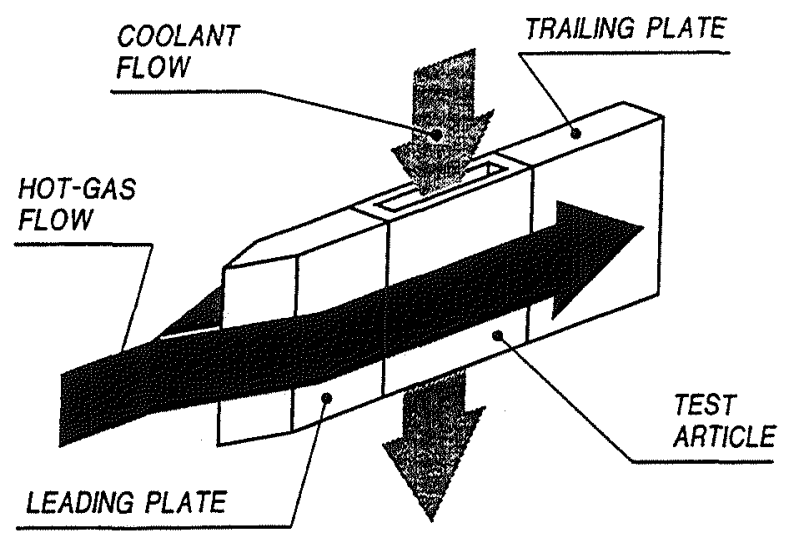

Fig. 6 Concept of heat transfer rig.

In the test rig, the heated air flows from a plenum, on the left, through the test section with a vertically located flat plate, and exits to the right into an exhaust system. The flat plate in the test section consists of a leading plate on the left, a cooled segment in the middle -- the test module, and a trailing plate on the right. The leading plate is replaceable; thus, the Reynolds number of the external flow in the test module region, which is based on the distance from the leading edge, can be set to various levels at identical 
heated air flow conditions. Of course, the external flow Reynolds number can be also controlled by varying flow conditions and keeping the same leading plate section.

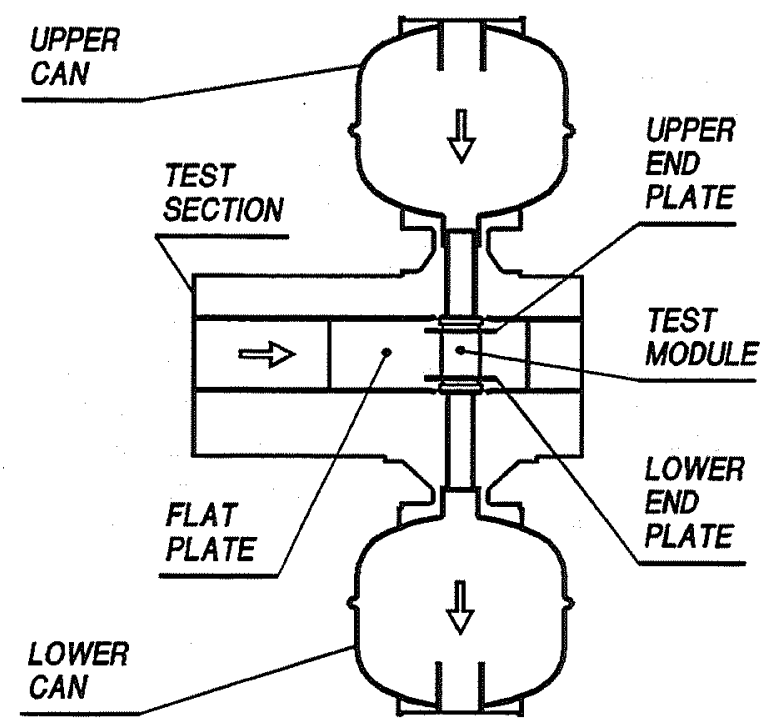

Fig. 7 Simplified section of the heat transfer test rig.

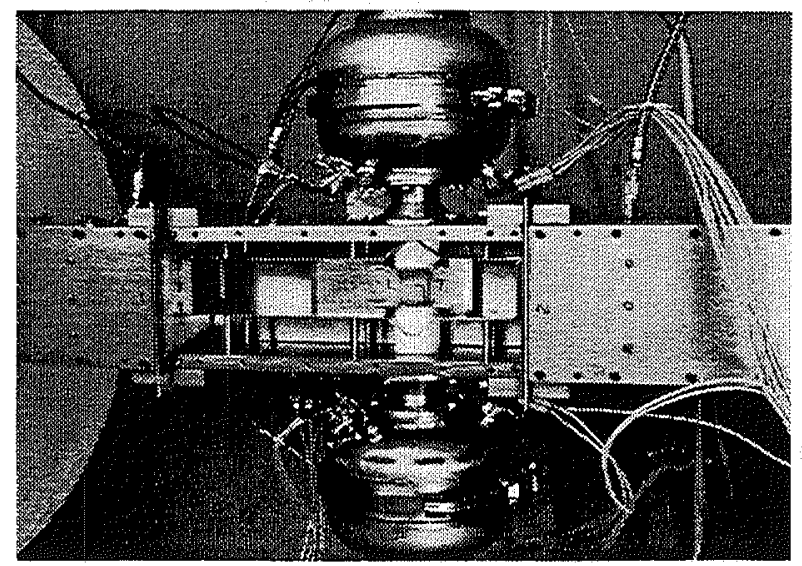

Fig. 8 Overall view of the heat transfer test rig.

The cooling air flows in the vertical direction through the inlet plenum (upper can), the test module, and the exit plenum (lower can). The coolant flow total parameters were measured in both the inlet and exit plenums. The mass flow of the coolant stream was measured upstream of the inlet plenum. Both plenums are carefully insulated using macor lining. Fig. 9 shows the inlet plenum without a cover and macor lining. A flow spreader (conical screen) and an instrumentation ring beneath the spreader are visible here. The instrumentation ring holds four totalpressure and four total-temperature probes. The lower plenum is equipped similarly.

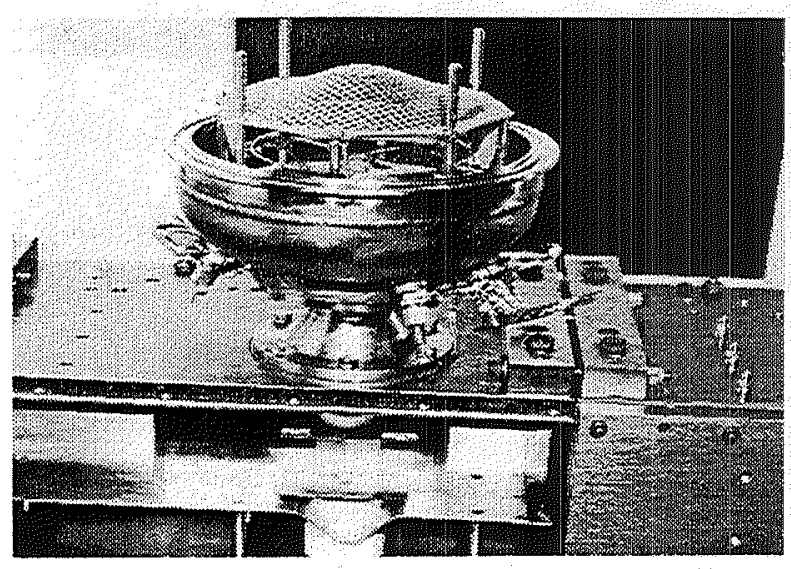

Fig. 9 Coolant inlet plenum.

The entire test rig was designed to be highly modular. For example, both coolant plenums (upper and lower cans) are self-contained components (including the instrumentation). They can be separated very easily from the test section. The test module with the coolant passage is also an independent unit. As demonstrated in Figs. 10 and 11, the test module can also be removed easily from the test section, allowing us to inspect and calibrate the thin film thermocouples on the test module without a major disruption to the test facility. Finally, a photograph in Fig. 12 shows additional details of the test section including the upper and lower end plates that determine the extent of the heat transfer area. The cross-section dimensions of the coolant passage are $21.0 \times 1.8 \mathrm{~mm}$. The size of the heat transfer area is $21.0 \times 51.1 \mathrm{~mm}$ (heat is transferred through both walls of the test module). The material of the test module is Inconel 718 . The nominal wall thickness is $1.4 \mathrm{~mm}$.

The heat transfer test rig is included in the Engine Component Instrumentation Development Facility at NASA Lewis Research Center. The facility is described in detail in Ref. 6 . The facility enables mass flow rates up to $1.13 \mathrm{~kg} \cdot \mathrm{s}^{-1}$, at absolute total inlet pressure of $380 \mathrm{kPa}$, and total inlet temperature of $533 \mathrm{~K}$. The facility uses electric air heaters to control the flow temperatures. The exhaust system can maintain a vacuum at $10 \mathrm{kPa}$ absolute pressure level. A unique capability of this facility is the auxiliary air 
supply and exhaust piping system that allows independent control of the coolant air flow for heat transfer experiments.

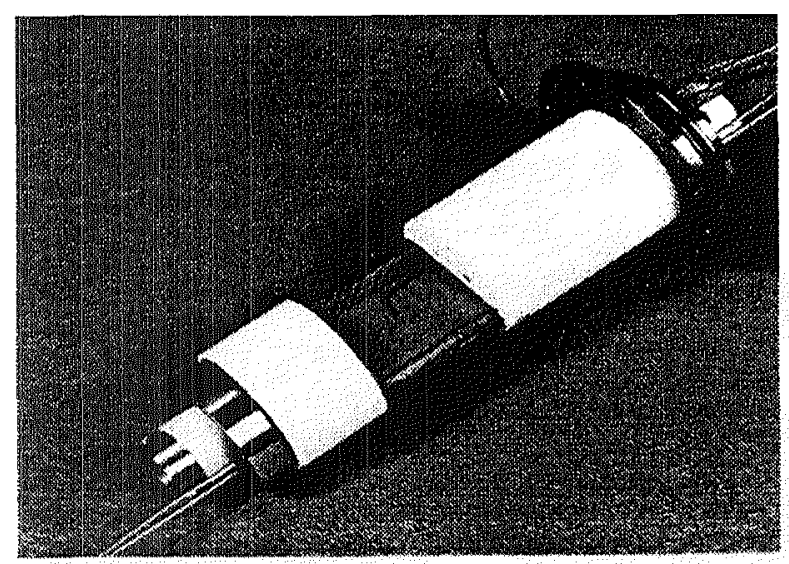

Fig. 10 Heat transfer test module.

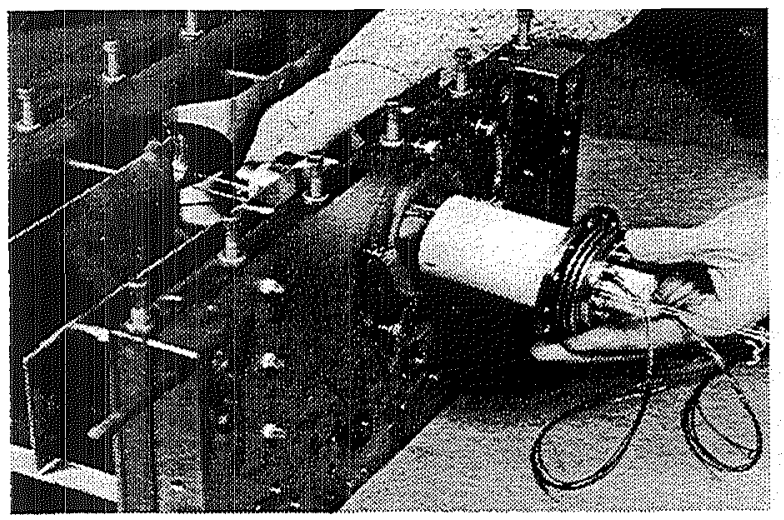

Fig. 11 Insertion of the test module into the test section.

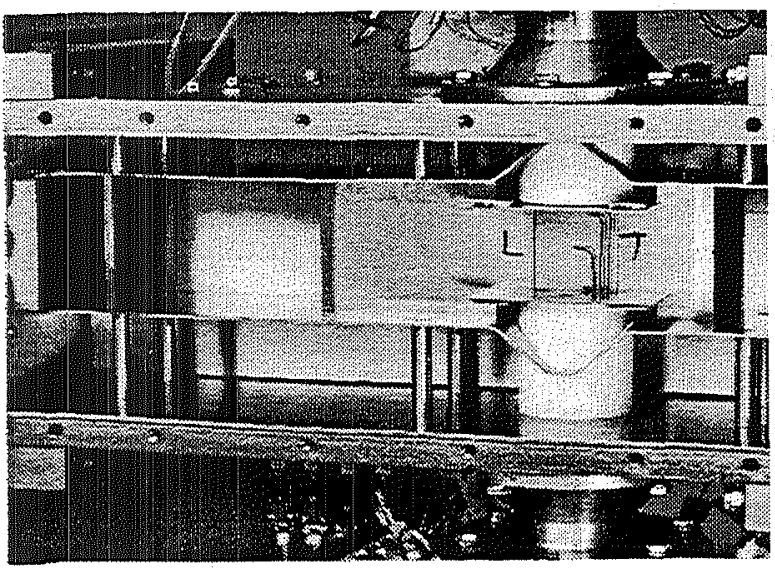

Fig. 12 Assembled test section.
As already mentioned, the test module was instrumented with four thin-film thermocouples on the external surface and four sensors on the internal surface of the same wall. The location of the sensors on the external wall is depicted in Fig. 13. The locations are labeled $L I$ through $L 4$ with a suffix $E$ for the external surface and a suffix $I$ for the internal one. Before the thermocouples were made, the local wall thicknesses were recorded. Thus at each location, the pair of thermocouples, known wall thickness, and known material properties constitute a well defined local heat transfer sensor for the assumption of onedimensional heat conduction. Two thin-film thermocouples, at locations $L 1_{-} E$ and $L A E E$, exhibited lower resistance to the ground than seemed reliable. Therefore, the signals from these two sensors were not recorded during testing; instead, tests were performed with only two heat-flux sensors at locations $L 2$ and $L 3$.

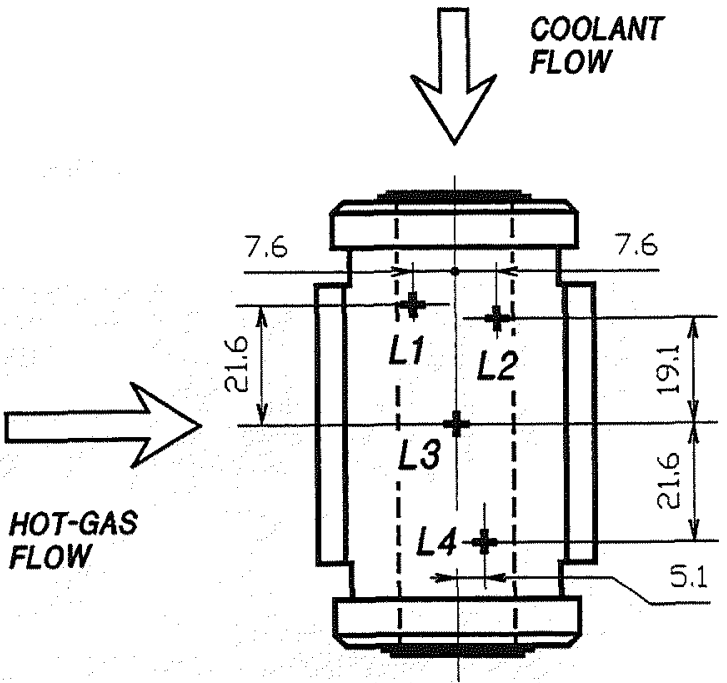

Fig. 13 Location of heat transfer sensors; the thinfilm thermocouples are on both external and internal surfaces of the test module (dimensions in $\mathrm{mm}$ ).

\section{Heat Transfer Measurements}

The tests reported in this paper were performed at three distinct operating conditions on the hot-gas side. The conditions are summarized in Tab. 1 . The characteristic length in the hot-gas Reynolds number, $\mathrm{Re}_{\mathrm{H}_{-}}$, is the distance from the leading edge of the flat plate to the centerline of the test module. Only one 


\begin{tabular}{|ll|c|c|c|}
\hline & & Test. cond. I & Test. cond. II & Test cond. III \\
\hline Flow velocity & {$\left[{\left.\mathrm{m} \cdot \mathrm{s}^{-1}\right]}\right.$} & $113.0 \pm 2.9$ & $162.3 \pm 1.8$ & $135.3 \pm 1.2$ \\
Abs. static pressure & {$[\mathrm{kPa}]$} & $92.61 \pm 1.11$ & $88.64 \pm 0.73$ & $163.78 \pm 1.16$ \\
Static temperature & {$[\mathrm{K}]$} & $379.7 \pm 0.6$ & $417.3 \pm 0.5$ & $422.5 \pm 4.4$ \\
Mach number & & $0.29 \pm 0.01$ & $0.40 \pm 0.01$ & $0.33 \pm 0.01$ \\
Reynolds number & & $553,600 \pm 13,300$ & $647,000 \pm 8,200$ & $976,200 \pm 18,200$ \\
\hline
\end{tabular}

Tab. 1 Test conditions; hot-gas side.

\begin{tabular}{|ll|c|c|c|c|c|}
\hline Mass flow rate & {$\left[\mathrm{g} \cdot \mathrm{s}^{-1}\right]$} & 7.79 & 9.40 & 13.38 & 16.94 & 20.22 \\
Flow velocity & {$\left[\mathrm{m} \cdot \mathrm{s}^{-1}\right]$} & 136.1 & 154.5 & 168.4 & 173.6 & 177.6 \\
Abs. static pressure & {$[\mathrm{kPa}]$} & 127.41 & 134.64 & 174.10 & 212.60 & 246.92 \\
Static temperature & {$[\mathrm{K}]$} & 289.4 & 287.5 & 284.7 & 283.1 & 281.8 \\
Mach number & & 0.40 & 0.46 & 0.50 & 0.52 & 0.53 \\
Reynolds number & & 38,120 & 46,260 & 66,310 & 84,320 & 101,070 \\
\hline
\end{tabular}

Tab. 2 Test conditions; coolant side.

leading edge plate was used. The distance from the leading edge to the centerline of the test module is $126.9 \mathrm{~mm}$. The-hot gas flow parameters were determined from the total pressure and total temperature measurements in the hot stream $10 \mathrm{~mm}$ above the surface of the test module, and a static wall pressure measurement. Probe locations faced the centerline of the test module.

On the coolant side, the mass flow rate was varied step-wise from 5 to $25 \mathrm{~g} . \mathrm{s}^{-1}$ by increasing the coolant inlet total pressure, which resulted in the Reynolds number range from 25,000 to 110,000 . The test conditions for several Reynolds numbers, $R e_{C} O$, are given in Tab. 2. The characteristic length in the coolant Reynolds number is the hydraulic diameter of the cooling passage $(3.28 \mathrm{~mm})$. The total pressure and total temperature levels of the coolant flow were measured in the upper can. The measured values were used to calculate isentropic static parameters at the entrance section of the coolant passage. These parameters were used to calculate the coolant flow entrance Reynolds number, $R e_{C_{-} O}$.

Generally, two kinds of measurements were performed: bulk heat flow rate and local heat flow rates. The total heat transfer and bulk heat flow rate were determined based on the difference between the total exit and inlet coolant temperatures and the coolant mass flow rate. The inlet and exit coolant total temperatures were measured in the upper and lower coolant plenums, respectively. For the assumption of one-dimensional heat conduction, the local heat flow rates were determined from the wall surface temperatures (measured by the thin-film thermocouples), measured local wall thicknesses, and known metal heat conductivity. The wall temperatures for the locations $L 2$ and $L 3$ indicate that temperature gradients across the wall are 20 to 40 times larger than temperature gradients along the wall. The assunaption of one-dimensional heat conduction for these locations is therefore valid. In general, the results are quite encouraging for application of thin-film thermocouples for heat transfer experiments; at the moment, our confidence is based on the fact that local and bulk heat flow rates, which were measured by different methods, are mutually consistent.

The total heat transfer as a function of the coolant Reynolds number, $R e_{C}$, recorded for three hot-gasside flow conditions, is shown in Fig. 14. As can be seen here, the total heat transfer increases with increasing coolant Reynolds number, hot-gas Reynolds number, as well as with the increasing temperature difference between the hot and coolant sides. The overall heat transfer coefficient for the test module, $U_{T}$, 
is plotted in Fig. 15. The overall heat transfer coefficient was calculated from the bulk temperature rise of the cooling air, the total heat transfer area (two walls), and the difference between static temperatures for the hot-gas and coolant sides. The static temperature for the hot-gas side was calculated from measured hot-gas parameters at the test module location. The coolant static temperature we used was the one calculated for the entrance into the cooling passage.

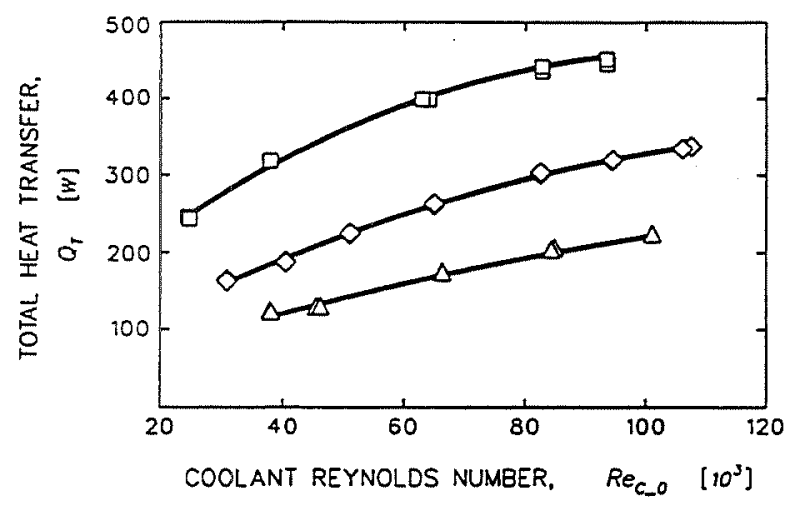

Fig. 14 Total heat transfer for the cooling passage (for symbols see Tab. 3).

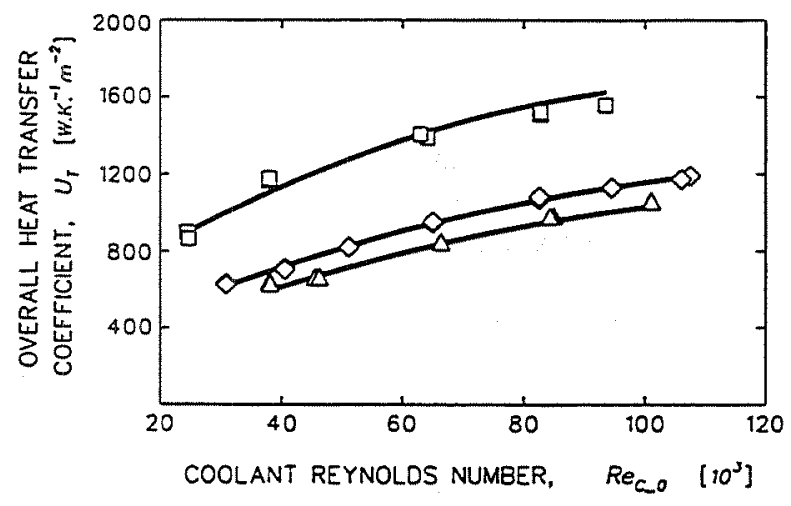

Fig. 15 Overall heat transfer coefficient for the cooling passage (for symbols see Tab. 3 ).

Our interest focused on comparison of bulk and local heat flow rate results. Fig. 16 shows average heat flow rate determined from the total heat transfer, measured on the coolant side, and the heat transfer area. Figs. 17 and 18 show local heat flow rates for locations $L 2$ and $L 3$, respectively. Local heat flow rates were determined from thin-film thermocouple readings across the test module wall. A rigorous comparison would require us to determine the distribution of local heat flow rates over the heat transfer area, average it, and then compare it with the

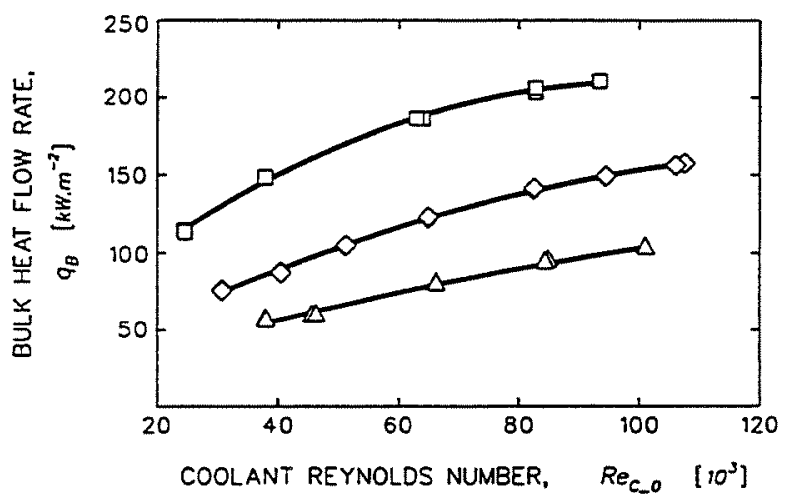

Fig. 16 Bulk heat flow rate (for symbols see Tab. 3).

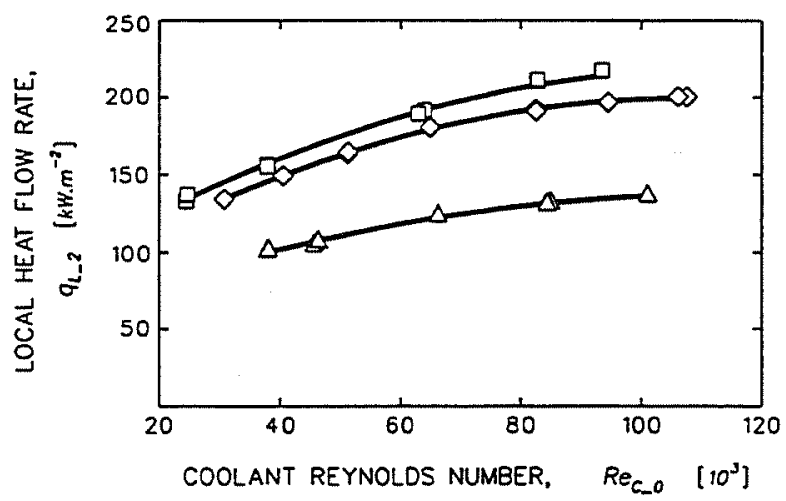

Fig. 17 Local heat flow rate at $L 2$, entrance to the test module (for symbols see Tab. 3).

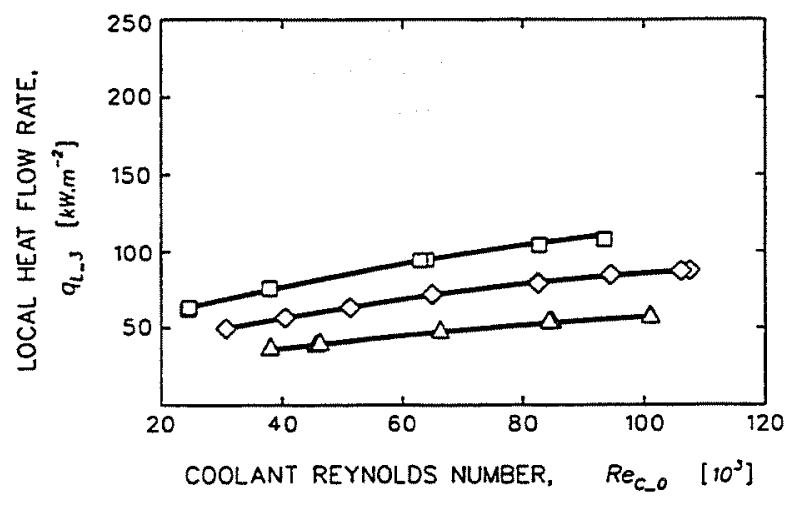

Fig. 18 Local heat flow rate at $L 3$, middle of the test module (for symbols see Tab. 3). 


\begin{tabular}{|c|c|c|}
\hline$\square$ & Test cond. III; & $\begin{array}{l}R e_{H_{-} 3}=976 * 10^{3} \\
\Delta T_{S_{-} H C}=131 \mathrm{~K}\end{array}$ \\
\hline$\diamond$ & Test cond. II; & $\begin{array}{l}R e_{H_{-} 3}=647 * 10^{3} \\
\Delta T_{S_{-} H C}=128 \mathrm{~K}\end{array}$ \\
\hline$\Delta$ & Test cond. I; & $\begin{array}{l}R e_{H_{-} 3}=554 * 10^{3} \\
\Delta T_{S_{-} H C}=94 \mathrm{~K}\end{array}$ \\
\hline
\end{tabular}

Tab. 3 Test conditions, assignment of symbols (Figs. 14 through 18).

measured bulk heat flow rate. We cannot do that because we have data for only two points ( $L 2$ and $L 3$ ) over an area where the distribution of the local heat flow rates is not uniform. Nevertheless, useful conclusions can still be made.

First, local heat flow rates in location $L 2$ should be noticeably higher than the bulk rate for the following two reasons. The temperature difference (hot-gas versus coolant) will be larger here, and the entrance effects will be quite pronounced here. On the other hand, it is reasonable to expect that the local heat flow rate at location $L 3$ will be less than the bulk one because the local heat flow rate distribution in the coolant flow direction is non-linear with high values at the entrance. Data in Figs. 16 through 18 fully confirm that expectation for the two lower

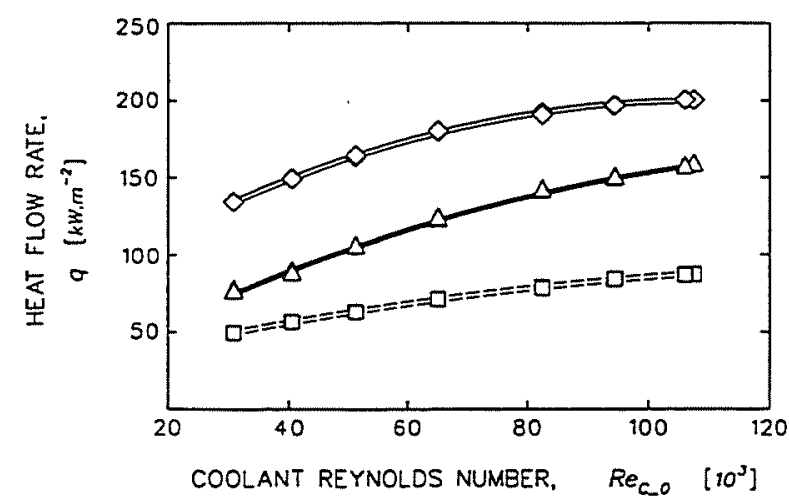

Fig. 19 Comparison of bulk and local heat flow rates at $\operatorname{Re}_{H_{3} 3}=647^{*} 10^{3}$ (solid line - bulk heat flow rate; double line - local heat flow rate at $L 2$; broken double line - local heat flow rate at $L 3$ ). hot-gas side Reynolds numbers $\left(\operatorname{Re}_{H_{3}}=554 * 10^{3}\right.$ and $\operatorname{Re}_{\mathrm{H}_{3}}=647^{*} 10^{3}$ ). Fig. 19 supports this discussion showing the data for the medium gas-side Reynolds number. For the highest gas-side Reynolds number of $976^{*} 10^{3}$, however, the increase of the local heat flow rate at station $L 2$ is less, relative to the bulk rate, than it was for the two lower Reynolds numbers. At present, we do not have enough data to comment on this observation.

In general, experimental data acquired from thinfilm thermocouples and their trends agree very well very with data acquired on the coolant side using conventional thermocouples. The results demonstrate usability of thin-film thermocouples for the upcoming warm turbine tests.

\section{Conclusions}

The following lessons and conclusions emerged during this study:

- most important, we verified the technology of applying thin-film thermocouples to local heat transfer measurements

- advances in the thin-film technology and a novel way of splicing the thin films to thick lead wires make it possible to apply thin-film thermocouples successfully to engine component testing

- the newly designed heat transfer test facility proved suitable for heat transfer measurements in engine size narrow cooling passages

- local heat transfer data indicate significant increase of heat flow rate in the entrance region of a cooling passage

- measured heat flow rates will serve as a data base for verifying analytical predictions for heat transfer in narrow rectangular passages with a high aspect ratio

The results confirmed our confidence about using thin-film thermocouples for the upcoming warm turbine tests at NASA LeRC. 


\section{Acknowledgement}

The authors are grateful to Dr. L.J. Bober of the NASA LeRC Propulsion Systems Division and Mr. K.C. Civinskas of the Turbomachinery Technology Branch of for their continuing support.

\section{References}

1. Grant, H.P. and Przybyszewski, J.S, and Claing, R.G., "Turbine Blade Temperature Measurements Using Thin Film Temperature Sensors," NASA CR-165201, 1985.

2. Englund, D.R. and Seasholtz, R.G., "Advanced High-Temperature Instrumentation for Hot Section Research Applications," Transaction of the ASME, Journal of Engineering for Gas Turbines and Power, Vol. 111, No. 1, 1989, pp. 103-113.
3. Liebert, C.H., Mazaris, G.A., and Brandhorst, W., "Turbine Blade Metal Temperature Measurements with a Sputtered Thin Film Chromel-Alumel Thermocouple," NASA TM $X-71844,1975$.

4. Grant, H.P. and Przybyszewski, J.S., "Thin Film Temperature Sensors," NASA CR-159782, 1980.

5. Kim, W.S. and Barrows, R.F., "Prototype ThinFilm Thermocouple/Heat-Flux Sensor for a Ceramic-Insulated Diesel Engine," DOE/NASA/50162-1, NASA TM-100798, 1988.

6. Bruckner, R.J., Buggele, A.E., and Lepicovsky, J., "Engine Component Instrumentation Development Facility at NASA Lewis Research Center," NASA TM-105644, 1992, (also AIAA paper ALAA-92-3995, 1992). 
Public reporting burden for this collection of information is estimated to average 1 hour per response, including the time for reviewing instructions, searching existing data sources, gallo Davis Highway, Suite 1204, Arlington, VA 22202-4302, and to the Office of Management and Budget. Paperwork Reduction Project (0704-0188). Washington, DC 20503.

\begin{tabular}{|l|c|c|}
\hline 1. AGENCY USE ONLY (Leave blank) & $\begin{array}{c}\text { 2. REPOAT DATE } \\
\text { October } 1995\end{array}$ & $\begin{array}{r}\text { 3. REPORT TYPE AND DATES COVERED } \\
\text { Technical Memorandum }\end{array}$ \\
\hline
\end{tabular}

4. TITLE AND SUBTTILE

Application of Thin-Film Thermocouples to Localized

Heat Transfer Measurements

6. AUTHOR(S)
5. FUNDING NUMBERS

WU-505-62-10

J. Lepicovsky, R.J. Bruckner, and F.A. Smith

\section{PERFORMING ORGANIZATION NAME(S) AND ADDRESS(ES)}

National Aeronautics and Space Administration

Lewis Research Center

Cleveland, Ohio 44135-3191
8. PERFORMING ORGANIZATION REPORT NUMBER

E-9890

9. SPONSORINGMONITORING AGENCY NAME(S) AND ADDRESS(ES)

10. SPONSORING/MONITORING AGENCY REPORT NUMBER

National Aeronautics and Space Administration

Washington, D.C. 20546-0001

NASA TM-107045

11. SUPPLEMENTARY NOTES

Prepared for the 31st Joint Propulsion Conference and Exhibit cosponsored by AIAA, ASME, SAE, and ASEE, San Diego, California, July 10-12, 1995. J. Lepicovsky, NYMA, Inc., 2001 Aerospace Parkway, Brook Park, Ohio 44142 (work funded by NASA Contract NAS3-27186); R.J. Bruckner and F.A. Smith, NASA Lewis Research Center. Responsible person, R.J. Bruckner, organization code $2840,(216) 433-6499$.

12a. DISTRIBUTIONAVAILABILITY STATEMENT

Unclassified -Unlimited

Subject Category 07

This publication is available from the NASA Center for Aerospace Information, (301) 621-0390.

13. ABSTRACT (Maximum 200 words)

The paper describes a proof-of-concept experiment on thin-film thermocouples used for localized heat transfer measurements applicable to experiments on hot parts of turbine engines. The paper has three main parts. The first part describes the thin-film sensors and manufacturing procedures. Attention is paid to connections between thin-film thermocouples and lead wires, which has been a source of problems in the past. The second part addresses the test arrangement and facility used for the heat transfer measurements modeling the conditions for upcoming warm turbine tests at NASA LeRC. The paper stresses the advantages of a modular approach to the test rig design. Finally, we present the results of bulk and local heat flow rate measurements, as well as overall heat transfer coefficients obtained from measurements in a narrow passage with an aspect ratio of 11.8 . The comparison of bulk and local heat flow rates confirms applicability of thin-film thermocouples to upcoming warm turbine tests.

14. SUBJECT TERMS

Heat transfer; Thin film thermal couples; Internal cooling; Experimental technologies

17. SECURTYY CLASSIFICATION OF REPORT Unclassified

18. SECURTYY CLASSIFICATION
OF THIS PAGE
Unclassified
Unclassified

\section{SECURITY CLASSIFICATION OF ABSTRACT} Unclassified 